Vol.01/ No. 02

Pages: 83- 92

https://www.irojournals.com/iroeea

DOI: https://doi.org/10.36548/jeea.2019.2.003

\title{
AGRICULTURAL MACHINE AUTOMATION USING IOT THROUGH ANDROID
}

\author{
Dr. Abul Bashar \\ Department of Computer Engineering \\ Prince Mohammad Bin Fahd University \\ Al Khobar, Kingdom of Saudi Arabia - 31952 \\ Email: abashar@pmu.edu.sa
}

\begin{abstract}
The agriculture still remains the fundamental source of livelihood for fifty percentage of the Indian population. It is most significant sector of the Indian economy as eighteen percentage of the India's Gross domestic product is accounted from Indian Agricultural sectors. The government concentrates on enhancing the GDP of the Agricultural products by the applying the latest methodologies and the advanced technologies. All the emerging technologies can help out in increasing the yield crops by maintaining the suitable conditions for the crop growth. The proposed method in the paper utilizes the android application to automate the machines that are used in the agriculture with the help of internet of things. The machine automation ensures that the works are done automatically without any human intervention.
\end{abstract}

Keywords: Agriculture, Machine Automation, Android App, Internet of Things, Micro Controller and Zigbee Devices

\section{INTRODUCTION}

The latest advancements in the technology has impacted almost all areas of life and a wider range of applications, such as smart phones, smart vehicles and smart controlling devices. Though the technology has brought in innumerable sophistications in various fields. The Indian agriculture still remains unbothered as the farmers hesitate to adopt to the changing innovations keeping in mind the cost and the complexities in implementation and maintenance.

Though agriculture is the source of the fundamental occupation in India and remains as the vital sector of the Indian economy, accounting $18 \%$ of the Indian Gross domestic production. The usage of the advanced technologies in agriculture are still in infant stage as the farmers are not aware of the technologies that could support their farming lands and their uses.

ISSN: 2582-3051 
Journal of Electrical Engineering and Automation (EEA) (2019)

Vol.01/ No. 02

Pages: 83- 92

https://www.irojournals.com/iroeea

DOI: https://doi.org/10.36548/jeea.2019.2.003

The evolution of the smart phones and the latest developments in the information and the communication systems have caused considerable changes in the various applications and in the recent years, it has been put in use in monitoring the soil moisture and the crop growth in the agriculture.

The prevailing system in the agriculture informs the farmer about the soil moisture and the crop growth through the android application and requires the human assistance to water the fields and take care of the crops. To bring in the automation in the process of cultivating, farming and irrigation. The proposed system aims in developing an automated machines for the cultivation, irrigation and the farming in the agricultural lands using the Internet of things.

The proposed system allows the farmers to Tele-monitor the equipment's used in the farming such as the tractors the motors etc. and control the same. The microcontroller used in the system is programmed with the capability to ensure that every process required for the plant growth is done perfectly, the zigbee is used for extending the communication between the machines and the controller. The internet is utilized to convey the information from the controller to the farmer through the android application. The waspmote sensors are employed in monitoring the soil moisture, the humidity, water quantity, crop diameter, length and the wind speed etc.

So the proposed system enhances the yield of the crops without the intervention of the farmers. The remaining paper is organized with the related works detailing the automation achieved using the internet of things in various fields in section 2. The Proposed automated farming system in section 3, the Result analysis in section 4 and the conclusion in section 5 .

\section{RELATED WORKS}

The related works explains the use of the utilization of the internet of things in various applications that are as follows. The author Valanarasu, et al [1] details the "smart and secure iot and ai integration framework for hospital environment" Smys, S et al [2] describes the "Robot Assisted Sensing, Control and Manufacture in Automobile Industry." Duraipandian, et al [3] presents the "cloud based internet of things for smart connected objects."

ISSN: 2582-3051 
Journal of Electrical Engineering and Automation (EEA) (2019)

Vol.01/ No. 02

Pages: 83- 92

https://www.irojournals.com/iroeea

DOI: https://doi.org/10.36548/jeea.2019.2.003

Pandian, A. Pasumpon. et al [4] details the "artificial intelligence application in smart warehousing environment for automated logistics." Raj, Jennifer S et al [5] provides the details of the "Automation Using Iot in Greenhouse Environment." Raj, J. S et al [6] elaborates the "Internet of Things and Big Data Analytics for Health Care with Cloud Computing" Kumar et al [7] details the "A novel report on architecture, protocols and applications in Internet of Things (IoT).”

Robert Bestak et al [8] puts forth the "'Introduction to the Special Issue on Inventive Network Structures for Next Generation Wireless Personal Systems." Akash Raj, et al [9] details the "IoT based Agro Automation System using Machine Learning Algorithms." Sujith, et al [10] has put forward the "Automated Agriculture as a Service Using IoT." International Journal 7, no. 5 (2017). Mandula, et al [11] "Mobile based home automation using Internet of Things (IoT)."

Chen, et al [12] presents the "Automated monitoring system for the fish farm aquaculture environment." Chate, et al [13] provides the "Smart irrigation system using raspberry pi." Pavithra, et al [14] details the. "GSM based automatic irrigation control system for efficient use of resources and crop planning by using an Android mobile." Patil, et al [15] presents the "Precision Agriculture: A Survey." Madli et al [16] details the "Intelligent irrigation control system using wireless sensors and android application." Negrete et al [17] presents the review on "Arduino board in the automation of agriculture in Mexico"

\section{PROPOSED AUTOMATED MACHINE FOR AGRICUTURE}

The process of farming is not simple, the farmer initially cultivates the soils for the sowing by preparing the soil, and once the soil is prepared, the seeds are sowed. After the process of the sowing the irrigation process is followed by watering the crops properly. The above mentioned process utilizes the machines and requires the human intervention to do all the process and in unavoidable situations the farmer even fails to irrigate the lands properly leading to decrease in the yield of the crop. So in order to avoid such situations and increase the crop yield the proposed system introduces automation for all the process involved in the crop growing. Basically the crop growing involves three phases where the initial phase is the cultivation, the second phase is the sowing and the third phase is the reaping. The flow diagram shown in the figure.1below provides the programming steps of the controller in regulating the all the three phases in crop growing without the intervention of the humans.

ISSN: 2582-3051 
Journal of Electrical Engineering and Automation (EEA) (2019)

Vol.01/ No. 02

Pages: 83- 92

https://www.irojournals.com/iroeea

DOI: https://doi.org/10.36548/jeea.2019.2.003

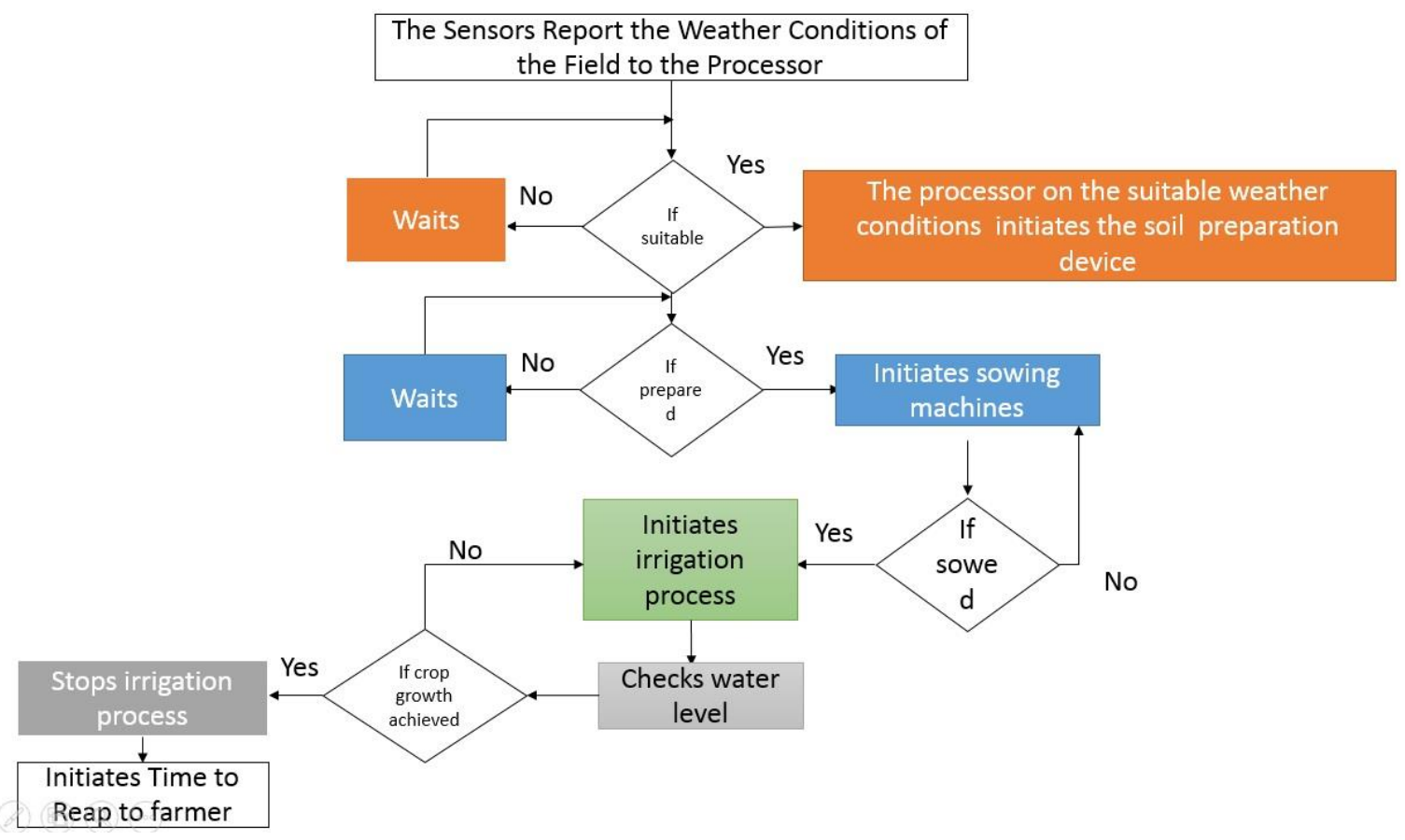

Fig.1 Proposed Flow Chart

The block Diagram below in fig. 2 shows the functioning of the proposed process involved in crop growing. The proposed system utilizes the beagle bone air processor to control all the actions the machines in the agriculture and conveys the information to the farmer.

ISSN: 2582-3051 
Journal of Electrical Engineering and Automation (EEA) (2019)

Vol.01/ No. 02

Pages: 83- 92

https://www.irojournals.com/iroeea

DOI: https://doi.org/10.36548/jeea.2019.2.003

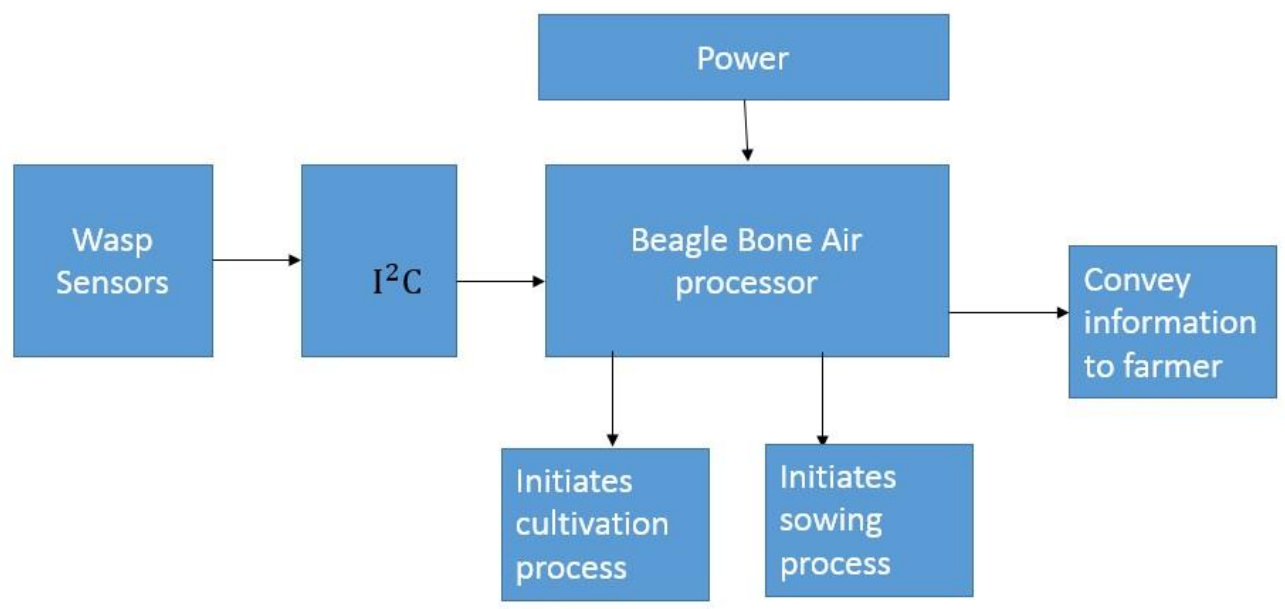

Fig.2 Proposed Block Diagram

\subsection{Hard Ware Description}

The table.1 below shows the hardware description of the components utilized in the proposed system.

ISSN: 2582-3051 
Journal of Electrical Engineering and Automation (EEA) (2019)

Vol.01/ No. 02

Pages: 83- 92

https://www.irojournals.com/iroeea

DOI: https://doi.org/10.36548/jeea.2019.2.003

\begin{tabular}{|c|c|}
\hline Hard ware used & Description \\
\hline $\begin{array}{l}\text { Beagle Bone Air } \\
\text { Processor }\end{array}$ & $\begin{array}{l}\text { SoC - Texas Instruments Sitara AM3358BZCZ100 Cortex A8 @ } 1 \mathrm{GHz} \text { with NEON + } \\
\text { PowerVR SGX530 GPU System Memory - 512 MB DDR3L @ } 800 \mathrm{MHz} \text { Storage - 4GB } \\
\text { eMMC + micro SD slot, } \\
\text { HS USB } 2.0 \text { client port (micro USB) } \\
\text { HS USB } 2.0 \text { host poty (USB type -A) } \\
\text { HS USB } 2.0 \text { host port on expansion header } \\
\text { 10/100M Ethernet (RJ45) } \\
\text { WiFi } 802.11 \mathrm{~b} / \mathrm{g} / \mathrm{n} \text { via Realtek RTL8188US with SMA connector for antenna } \\
\text { Bluetooth } 4.0 \text { LE via TI CC2541 with SMA connector for antenna } \\
\text { Zigbee via TI CC2531 with SMA connector for antenna } \\
\text { Expansion Headers Debug Ports - Optional onboard 20-pin JTAG, serial header (6-pin), BLE } \\
\text { and Zigbee debug pin Misc - Reset, boot, and power buttons Power Supply - 5VDC via 2- } \\
\text { pin header Dimensions }-86.36 \times 54.61 \mathrm{~mm}\end{array}$ \\
\hline Wasp mote Sensors & $\begin{array}{l}\text { Waspmote hardware architecture has been specially designed to work with extremely low } \\
\text { consumption. Digital switches allow to turn on and off any of the sensor interfaces as well as } \\
\text { the radio modules. Three different sleep modes make Waspmote the lowest consumption IoT } \\
\text { platform in the market }\end{array}$ \\
\hline Zigbee & $\begin{array}{l}\text { a low rate WPAN i.e., LR-WPAN that connects devices that operating in close sapce. } \\
\text { ZigBee uses mesh network, self organized, multihop with battery life time .In this network } \\
\text { two types of devices can operate namely FFD (Full Function Device), and RFD(Reduced } \\
\text { Function Device) .FFD acts in three forms PAN coordinator, a coordinator, device. } \\
\text { FFD can talk with RFD and FFD, but RFD talk only with FFD. RFD are used for simple } \\
\text { Applications After activating FFD for first time, it acts as PAN- Coordinator. Each star } \\
\text { network is differentiated from other, and PAN identifier can allow connections between } \\
\text { different stars. RFD is connected in cluster tree network }\end{array}$ \\
\hline I2C, IIC PCF 8591 & $\begin{array}{l}\text { Inter Integrated Circuit often shortened as I2C, IIC,I2C. It was developed as a } \\
\text { Communication Protocol to interact between different IC's, Sensors, Chips to Central } \\
\text { Processing Unit (CPU) i.e. Computer. It converts sensor Analog signals to Digital } \\
\text { signals. It is interaction between Low speed peripheral like sensors, keyboard with High } \\
\text { speed peripherals like processors }\end{array}$ \\
\hline Drivers & $\begin{array}{l}\text { Device is a monolithic integrated high voltage, high current four channel driver designed to } \\
\text { accept standard DTL or TTL logic levels and drive inductive loads (such as relays solenoids, } \\
\text { DC and stepping motors) and switching power transistors. It is used to drive the seeding } \\
\text { machine's motor, cultivation machine's motor and irrigation pump }\end{array}$ \\
\hline Controlled Devices & $\begin{array}{l}\text { CULTIVATION MACHINE: It is used to cultivate the farm automatically using smartphone. } \\
\text { SOWING MACHINE: It is useful for automatic seeding process in farm. IRRIGATION } \\
\text { PUMP: Irrigation pump runs automatically for supplying water to the farm. }\end{array}$ \\
\hline
\end{tabular}

Table.1 Hardware Description

ISSN: 2582-3051 
Journal of Electrical Engineering and Automation (EEA) (2019)

Vol.01/ No. 02

Pages: 83- 92

https://www.irojournals.com/iroeea

DOI: https://doi.org/10.36548/jeea.2019.2.003

The proposed system utilizing the beagle bone processor and the Waspmote sensors can adopt to the changing needs in the future as they can be programmed easily. The proposed model provides a flexible as well as an easy to use interface along with the high resistance to the noise. This ensures a fully automated system for the agriculture with very little man power engaged. The proposed systems allows a farmer to Tele- monitor the all the phases and control the process.

\subsection{The Android App}

All the parts of the proposed system are connected to the 4G network using the IP address. The information's and the complete details of the process taking place are updated to the cloud server, that responds according to the requests of the users. This generates an URL and the IP address to the convey the information's, the setup is installed in the processor and the IP address is generated for the processor through which the information are sent to and received from farmer using the android app. The android application is developed in python using the Bee Ware tools to regularly monitor and update the threshold level of the sensed details directly by transmitting signals to the processor over the internet.

\section{RESULTS}

The proposed system for the automating the machines in the agriculture is easy to set up as well as provides an effective Tele monitoring and control of $t$ the systems to the farmer. The process continues without fail until the crops are reaped. Once the crops are reaped after a certain number of days and once again the land is prepared for the farming of the next seasonal crop. The fig. 3 below shows the automated cultivation and the irrigation process achieved in the agricultural land using the proposed process.

ISSN: 2582-3051 
Journal of Electrical Engineering and Automation (EEA) (2019)

Vol.01/ No. 02

Pages: 83- 92

https://www.irojournals.com/iroeea

DOI: https://doi.org/10.36548/jeea.2019.2.003
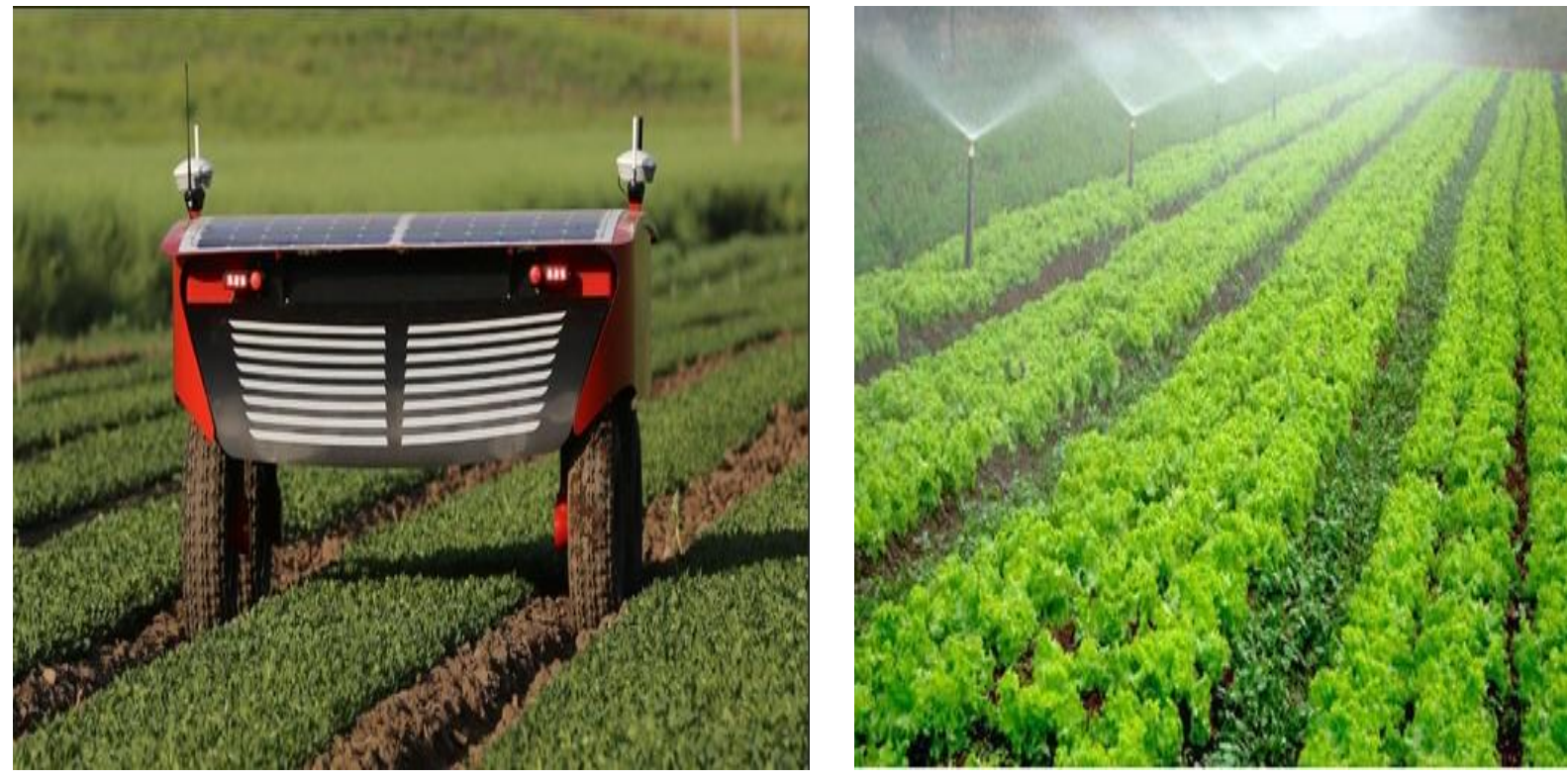

Fig .3 Automated Cultivation and Irrigation Process

\section{CONCLUSION}

The proposed system achieves the automation by employing the beagle bone air processor and the wasp mote sensors and many other hardware devices enabled by the internet of things. The yield of the agricultural lands could be improved by utilizing the proposed process and the weariness of the farmers can be reduced considerably by the Tele-monitoring and the control enabled by the proposed system.

\section{References}

[1] Valanarasu, Mr R. "SMART AND SECURE IOT AND AI INTEGRATION FRAMEWORK FOR HOSPITAL ENVIRONMENT." Journal of ISMAC 1, no. 03 (2019): 172-179.

[2] Smys, S., and G. Ranganathan. "ROBOT ASSISTED SENSING, CONTROL AND MANUFACTURE IN AUTOMOBILE INDUSTRY." Journal of ISMAC 1, no. 03 (2019): 180-187. 
Journal of Electrical Engineering and Automation (EEA) (2019)

Vol.01/ No. 02

Pages: 83- 92

https://www.irojournals.com/iroeea

DOI: https://doi.org/10.36548/jeea.2019.2.003

[3] Duraipandian, M., and Mr R. Vinothkanna. "CLOUD BASED INTERNET OF THINGS FOR SMART CONNECTED OBJECTS." Journal of ISMAC 1, no. 02 (2019): 111-119.

[4] Pandian, A. Pasumpon. "ARTIFICIAL INTELLIGENCE APPLICATION IN SMART WAREHOUSING ENVIRONMENT FOR AUTOMATED LOGISTICS." Journal of Artificial Intelligence 1, no. 02 (2019): 63-72.

[5] Raj, Jennifer S., and J. Vijitha Ananthi. "AUTOMATION USING IOT IN GREENHOUSE ENVIRONMENT." Journal of Information Technology 1, no. 01 (2019): 38-47.

[6] Smys, S., \& Raj, J. S. (2019). INTERNET OF THINGS AND BIG DATA ANALYTICS FOR HEALTH CARE WITH CLOUD COMPUTING. Journal of Information Technology, 1(01), 9-18.

[7] Kumar, R. Praveen, and S. Smys. "A novel report on architecture, protocols and applications in Internet of Things (IoT)." In 2018 2nd International Conference on Inventive Systems and Control (ICISC), pp. 1156-1161. IEEE, 2018.

[8] Smys, S., and Robert Bestak. "Introduction to the Special Issue on Inventive Network Structures for Next Generation Wireless Personal Systems." Wireless Personal Communications 90, no. 2 (2016): 421-422.

[9] Akash Raj, N., Balaji Srinivasan, D. Deepit Abhishek, J. Sarath Jeyavanth, and A. Vinith Kannan. "IoT based Agro Automation System using Machine Learning Algorithms." International Journal of Innovative Research in Science, Engineering and Technology (An ISO 3297: 2007 Certified Organization) Vol 5 (2016).

[10] Sujith, A. V. L. N., and K. Chandra Sekhar. "Automated Agriculture as a Service Using IoT." International Journal 7, no. 5 (2017).

[11] Mandula, Kumar, Ramu Parupalli, CH AS Murty, E. Magesh, and Rutul Lunagariya. "Mobile based home automation using Internet of Things (IoT)." In 2015 International Conference on Control, Instrumentation, Communication and Computational Technologies (ICCICCT), pp. 340-343. IEEE, 2015.

[12] Chen, Jui-Ho, Wen-Tsai Sung, and Guo-Yan Lin. "Automated monitoring system for the fish farm aquaculture environment." In 2015 IEEE International Conference on Systems, Man, and Cybernetics, pp. 1161-1166. IEEE, 2015.

[13] Chate, Bhagyashree K., and J. G. Rana. "Smart irrigation system using raspberry pi." International Research Journal of Engineering and Technology (IRJET) 3, no. 05 (2016): 247-249. 
Journal of Electrical Engineering and Automation (EEA) (2019)

Vol.01/ No. 02

Pages: 83- 92

https://www.irojournals.com/iroeea

DOI: https://doi.org/10.36548/jeea.2019.2.003

[14] Pavithra, D. S., and M. S. Srinath. "GSM based automatic irrigation control system for efficient use of resources and crop planning by using an Android mobile." IOSR Journal of Mechanical and Civil Engineering (IOSR-JMCE) 11, no. 4 (2014): 49-55.

[15] Patil, Shailaja, Anjali R. Kokate, and Dhiraj D. Kadam. "Precision Agriculture: A Survey." International Journal of Science and Research (IJSR) (2016).

[16] Madli, Rajeshwari, Santhosh Hebbar, Vishwanath Heddoori, and G. V. Prasad. "Intelligent irrigation control system using wireless sensors and android application." International Journal of Computer, Electrical, Automation, Control and Information Engineering 10, no. 8 (2016): 1424-1430.

[17] Negrete, Jaime Cuauhtemoc, Eugenio Romantchik Kriuskova, Gilberto De Jesus Lopez Canteñs, Christian Israel Zuñiga Avila, and Gamaliel Lopez Hernandez. "Arduino board in the automation of agriculture in Mexico, a review." International Journal of Horticulture 8 (2018).

ISSN: 2582-3051 